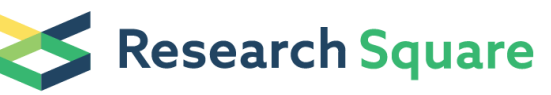 \\ Preprints are preliminary reports that have not undergone peer review. \\ They should not be considered conclusive, used to inform clinical practice, \\ or referenced by the media as validated information.
}

\section{Investigation on the Stiffness of Wire Web of Multi Wire Sawing Machine and Its Influence on Machining Accuracy}

jian qiu ( $\sim$ qiuj1981@163.com )

Shenyang Machine Tool (Group) CO., LTD

Shanbao Zhang

Shenyang Machine Tool (Group) CO., LTD

Rilai Fu

Shenyang Machine Tool (Group) CO., LTD

He Zhu

Shenyang Machine Tool (Group) CO., LTD

Guodong Yang

Shenyang Machine Tool (Group) CO., LTD

Yingkui Zou

Shenyang Machine Tool (Group) CO., LTD

Renpeng Ge

Shenyang Machine Tool (Group) CO., LTD

\section{Research Article}

Keywords: stiffness of wire web, stiffness matrix, sawing accuracy, sawing stiffness, cutting efficiency, wire bow

Posted Date: April 12th, 2021

DOI: https://doi.org/10.21203/rs.3.rs-380401/v1

License: (c) (i) This work is licensed under a Creative Commons Attribution 4.0 International License. Read Full License

Version of Record: A version of this preprint was published at The International Journal of Advanced Manufacturing Technology on August 4th, 2021. See the published version at https://doi.org/10.1007/s00170-021-07788-8. 


\title{
Investigation on the stiffness of wire web of multi wire sawing machine and its influence on
}

\section{machining accuracy}

\author{
Jian Qiu ${ }^{1,3}$, Shanbao Zhang ${ }^{1}$, Rilai Fu², He Zhu³ , Guodong Yang ${ }^{1}$, Yingkui Zou ${ }^{1}$, Renpeng Ge ${ }^{1,3}$ \\ 1 R \& D Center, Qingdao Gaoce Technology Co., LTD, Qingdao 266114, China \\ 2 Department of Tire Inspection, Qingdao Gaoce Technology Co., LTD., Qingdao 266114, China \\ 3 Design and Research Institute, Shenyang Machine Tool (Group) CO., LTD., Shenyang 110142, China
}

Abstract: Diamond wire sawing has gradually applied as the dominant way of silicon sawing in the photovoltaic and semiconductor industry. In the design and evaluation field of diamond wire sawing machine, little research on the static stiffness are presented. But in the design field of traditional metal cutting machine tools, stiffness is an extremely important performance index. The stiffness of wire web should be mastered to improve the machining accuracy of diamond wire sawing. The special significance of this study is that stiffness of wire web is considered to be the key index of multi wire sawing performance, as a result, wire lag and wire bow due to the loss of the stiffness of wire web could be minimized. Aiming at the problem of the stiffness of wire web, the measurement method, process and evaluation standard were proposed. The influence of the stiffness of wire web on the machining process, wire bow, cutting force, machining accuracy and other factors were studied.

Keywords: stiffness of wire web; stiffness matrix; sawing accuracy; sawing stiffness; cutting efficiency; wire bow

\section{Introduction}

At present, the main processing methods for silicon wafer are diamond wire sawing and slurry wire sawing $\left[{ }^{1},{ }^{2}\right]$. With the development of technology, diamond wire sawing has made great progress in efficiency and quality, but the reciprocating cutting problems such as wire marks and tension fluctuation are still need to improve $\left.{ }^{3}\right]$. Generally, the way to improve the processing quality is to use finer diamond wire, improve the synchronicity of moving parts, and increase wire speed and satisfy feed speed to improve tension loss, in order to give full play to the cutting capability of diamond wire to ensure the accuracy $\left[{ }^{4},{ }^{5}\right]$. In addition, as a special machine tool, the stiffness performance of multi wire sawing machine will also affect the processing quality.

In the design and evaluation of diamond wire sawing machine, little research on stiffness are presented. But in the field of traditional metal cutting machine tools, stiffness is an extremely important performance index. The support stiffness of machine tool should be properly designed for reducing both the ground disturbance vibration and the drive disturbance vibration $\left[{ }^{6}\right]$. The stiffness of the motion and running parts of the machine tool are considered as the key components that affect the processing efficiency and accuracy. In the research of the spindle stiffness, Sarenac $\left.{ }^{7}\right]$ considered spindle stiffness is the main contribution of the machine tool stiffness. Bearings, inter-distances relations and console length and other constructional parameters were emphasized. Yen $\left.{ }^{8}\right]$ investigated the different approaches on a servo control board and with the ability to change the servo control algorithms on a test machine tool to test the performance of servo stiffness. As for the design and modeling method of stiffness, many scholars have studied it from a long time ago, such as Schenk in 1939 [Error! Bookmark not defined.] proposed model of spindle as elastic beams. Daisuke Kono [Error! Bookmark not defined.] proposed a 3D stiffness model of a machine tool support using contact stiffness which was obtained by multiplying the unit contact stiffness by the real contact area. By using the proposed stiffness model, the natural frequency and vibration mode shape of a machine tool bed was predicted. Li [ $\left.{ }^{9}\right]$ introduced a novel approach for designing the stiffener layout inside large machine tools by applying the self-optimal growth principle of plant ramifications in nature.

As for the measurement methods of stiffness, several researches have been presented. Majda $\left[{ }^{10}\right]$ adopted a method of measuring machine tool stiffness based on the model of rigid body motion, which enabled measurements to be made in generalized coordinates, including measurements of translational and torsional stiffness. This allowed testing the stiffness of

\footnotetext{
* Corresponding author. Tel.: +8602425191396
}

E-mail address: qiuj1981@163.com(Jian Qiu) 
various medium-sized machine tools - lathes, milling machines. Laspas $\left[{ }^{11}\right]$ presented a novel measurement procedure to measure and identify full translational stiffness matrices of 5-axis machining centers using quasi-static circular trajectories. The research expanded the measurement procedure to a calibration procedure for 5-axis machining centers and identify rotational stiffness. Different from the measurement method, CAE method has been used in the research of machine tool stiffness for a long time. Huang $\left[{ }^{12}\right]$ introduced a single module method and a hybrid modeling method for analyzing the stiffness of machine tools by using CAE modelling.

Similar to the traditional machine tool design, in order to improve the machining accuracy of diamond wire sawing, the stiffness design of wire web should be considered as a design item. This is the main purpose of this paper. Because the movement form of DWS is simple as only one movement axis in the feed direction, its dynamic performance is less affected by the movement axis. The elastic diamond wire is different from the rigid tool of traditional machine tool, the influence of vibration on machining is limited by the damping effect of wire. Therefore, unlike the dynamic stiffness used to evaluate the dynamic performance of equipment $\left[{ }^{13}\right]$, the static stiffness is more suitable for the stiffness evaluation of wire web.

As the multi wire sawing machine tool is composed of many parts, each part will deform under the action of load, which will lead to the relative displacement between diamond wire and silicon ingot, the displacement is a comprehensive amount. The stiffness of a machine tool cannot be evaluated by the stiffness of a certain part, but refers to the capability of the whole machine tool to resist deformation under the action of cutting force $\left[{ }^{14}\right]$. Different from traditional machine tools, multi wire sawing machine tools use abrasive grains to slide silicon material through the relative movement of diamond wire, and the elastic deformation of diamond wire is significantly larger than other parts of the equipment $\left[{ }^{15}\right]$. In the actual machining, under the action of cutting load, the wire web will deform along the force direction to form a wire bow $\left[{ }^{16}\right]$. These deviations will bring adverse effects on the machining, such as lose of accuracy and the deterioration of surface roughness. If the stiffness of wire web can be accurately measured, it plays an important role in understanding the processing capability of diamond wire sawing machine tool, and improving the processing accuracy and efficiency. The static stiffness of the machine tool is mainly determined by the stiffness of diamond wire web, the static stiffness of wire web can be used as an important index to evaluate the performance of multi wire sawing machine tool. It will directly affect the machining accuracy, efficiency and surface quality. Therefore, measuring and evaluating the static stiffness of wire web is the basis to establish competitiveness of diamond wire sawing machine tool.

\section{Research method}

\subsection{Definition of stiffness of wire web}

The static stiffness of diamond wire web refers to the capability of the wire web to resist the relative position change caused by the static force in the specified direction, mainly in the feeding direction of the silicon ingot relative to the wire web. It is an important factor to improve the machining accuracy and stability of multi-wire machines. The static stiffness can be calculated by the ratio between the loading force and the deformation of diamond wire caused by the external force.

\subsection{Detection and calculation method of static stiffness}

The relationship between the magnitude of force and deformation is approximately linear. The average static stiffness can be calculated by the ratio of force increment to displacement increment. The data can also be processed by the successive difference method and the least square method to obtain the static stiffness.

The static stiffness is obtained by Eq.(1). In order to reduce the measurement error, the deformation under the action of multiple incremental forces is usually measured continuously, and then the equation is obtained by linear fitting. The coefficient of the linear equation is the static stiffness value of the wire web.

$$
K_{f}=F_{f} / D_{f}
$$

where, $F_{\mathrm{f}}$ is the loading force applied in the feed direction, $D_{\mathrm{f}}$ is the deformation in the feed direction caused by the load.

The stiffness measurement method of diamond wire web is shown in Fig. 1. The process is as follows: (1) The loading 
device moves and contacts the wire web according to the specified number of wires, then record the feed position. (2) Continue to increase the unit feed, record the corresponding force under this feed. (3) Increase the feed position in turn, and record the force under each feed increment until the wire bow of the wire web reaches a certain value and has enough strength when the measurement can be stopped after enough data.

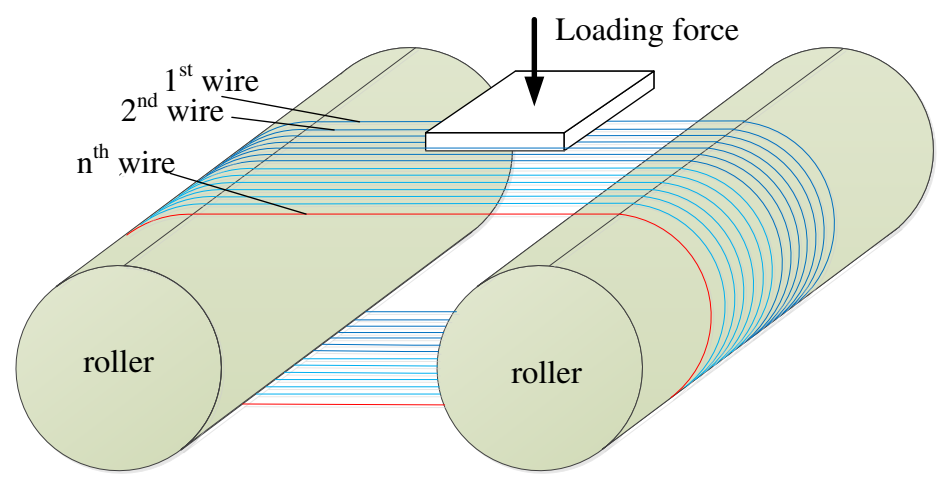

Fig. 1 Stiffness measuring principle of multi-wire sawing web

\section{Experiment}

3.1 DWS equipment and measuring instruments

(1) Sawing machine tool

The sawing equipment used in the experiment is a GC630S Multi wire sawing machine tool added tension adjusting function, as shown in Fig. 2. The silicon ingot is fixed on the force sensor which is set on the feed mechanism during the cutting test, while the press plate is fixed on the force sensor during the stiffness test.

(a)

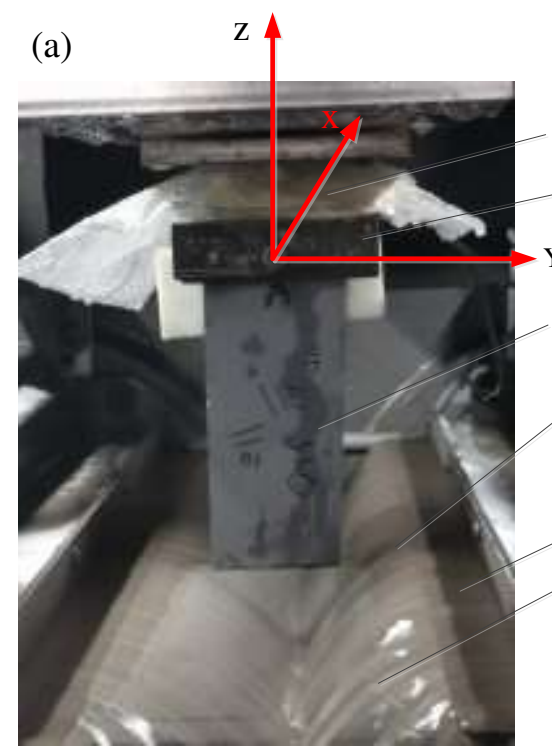

Fig. 2 Equipment used in the sawing test. (a. cutting test; b. stiffness test)

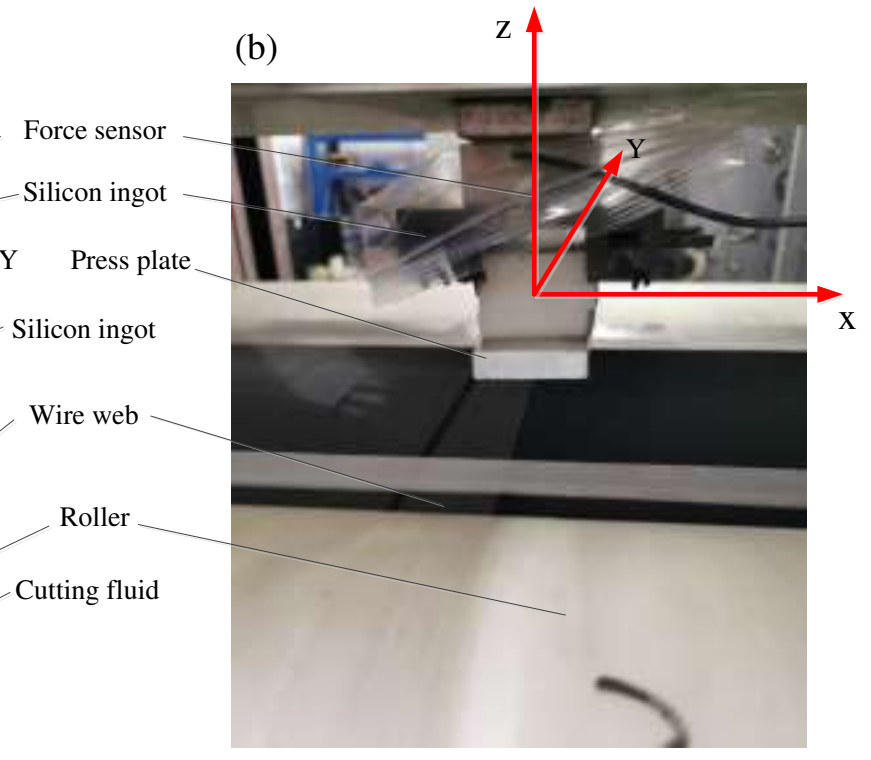

(2) Test instrument

The loading forces are measured by force measuring system consist of ME NC-3DT60 (K3D60) three component forces sensor and DASP V11 test system. The force is increased by equal spacing increment. The direction of the force action simulates the direction of multi wire sawing, that is, the feeding direction of silicon ingot. The action point of the force is concentrated on the middle position of silicon ingot and diamond wire in each experiment. The displacement test is recorded according to the actual feed rate displayed by the control system of the multi-wire sawing machine tool.

\subsection{Experimental design}

(1) Stiffness test of wire web 
The stiffness test of wire web is designed by changing the number of diamond wires that make up the wire web. It is repeated that the measurement method mentioned above to measure the static stiffness. In the test, the force sensor is placed on the workpiece feeding mechanism. The feed position along the feeding direction is taken as the reference position when force signal is changed. The feed rate is used to express the displacement. After the end of the first feed position, it stays for about $10 \mathrm{~s}$, and gradually incrementally presses down the wire web. Continue to press the wire web incrementally to realize deformation difference, measure the change of force and record the incremental displacement. After the end of force measurement at each subsequent feed position, the incremental displacement time is about $12 \mathrm{~s}$, and multiple force data corresponding to different positions is measured. The displacements and forces are recorded and taken as the data of static stiffness calculation. The experiment was carried out at ambient temperature of $20{ }^{\circ} \mathrm{C}$.

Table 1 Parameters of stiffness test

\begin{tabular}{|c|c|c|c|c|c|}
\hline No. & Wire speed, $\mathrm{m} / \mathrm{s}$ & Feed speed, $\mathrm{mm} / \mathrm{min}$ & Wire tension, $\mathrm{N}$ & Wire number & Preset feed distance, $\mathrm{mm}$ \\
\hline 1 & 0 & 10 & 6.5 & 5 & $3,6,9,12,15,18,21$ \\
\hline 2 & 0 & 10 & 6.5 & 10 & $3,6,9,12,15,18,21$ \\
\hline 3 & 0 & 10 & 6.5 & 15 & $3,6,9,12,15,18,21$ \\
\hline 4 & 0 & 10 & 6.5 & 20 & $3,6,9,12,15,18,21$ \\
\hline 5 & 0 & 10 & 6.5 & 25 & $3,6,9,12,15,18,21$ \\
\hline 6 & 0 & 10 & 6.5 & 30 & $3,6,9,12,15,18,21$ \\
\hline 7 & 0 & 10 & 6.5 & 35 & $3,6,9,12,15,18,21$ \\
\hline 8 & 0 & 10 & 6.5 & 40 & $3,6,9,12,15,18,21$ \\
\hline
\end{tabular}

The diamond wire used in the static stiffness test is 50 core wire with a diameter of $0.066 \mathrm{~mm}$ and a preset tension of 6.5 $\mathrm{N}$ in the test.

\section{(2) Cutting test}

The wire web composed of different number of wires is used to cut different lengths to sawing kerfs. The system parameters and cutting forces in the sawing process are recorded, and the wire bows generated during sawing are indirectly measured by the formed kerfs, so as to evaluate the influence of wire web stiffness on sawing accuracy. The process used in the test is shown in the Table 2, and part of the silicon material used in this research is shown in Fig. 3.

Table 2 Parameters of cutting test

\begin{tabular}{cccccccc}
\hline No. & Wire speed, $\mathrm{m} / \mathrm{s}$ & Feed speed, $\mathrm{mm} / \mathrm{min}$ & Wire tension, $\mathrm{N}$ & Wire providing, $\mathrm{m}$ & Wire receiving, $\mathrm{m}$ & Wire number & Preset feed distance, mm \\
\hline $1-8$ & 1500 & 1.5 & 6.5 & 600 & 595 & 5 & $5,10,15,20,25,30,35,40$ \\
$9-16$ & 1500 & 1.5 & 6.5 & 600 & 595 & 595 & $5,10,15,20,25,30,35,40$ \\
$17-24$ & 1500 & 1.5 & 6.5 & 600 & 595 & 15 & $5,10,15,20,25,30,35,40$ \\
$25-32$ & 1500 & 1.5 & 6.5 & 600 & 595 & 50 & $5,10,15,20,25,30,35,40$ \\
$33-40$ & 1500 & 1.5 & 6.5 & 600 & 595 & 30 & $5,10,15,20,25,30,35,40$ \\
$41-48$ & 1500 & 1.5 & 6.5 & 600 & 595 & 40 & $5,10,15,20,25,30,35,40$ \\
\hline
\end{tabular}

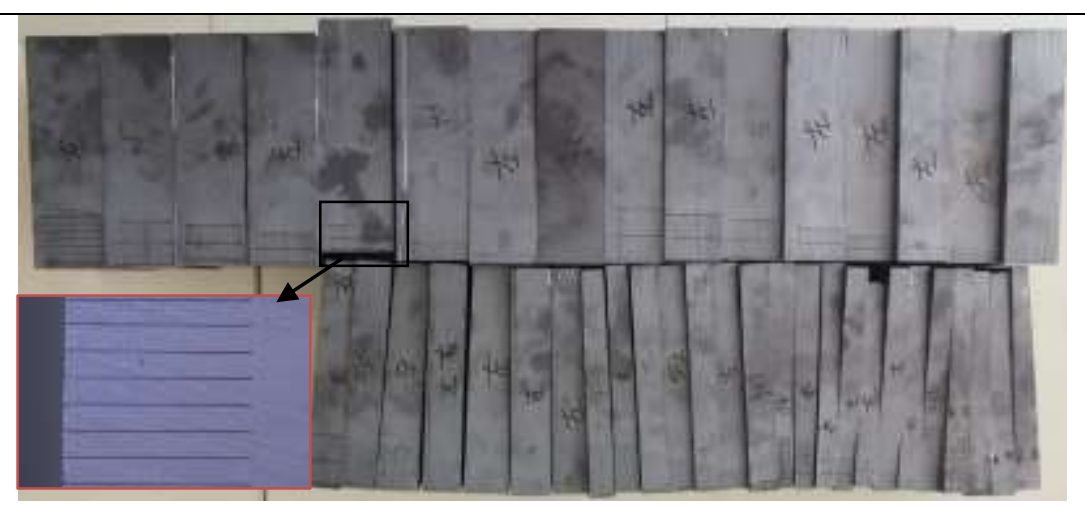

Fig. 3 Silicon workpiece used in the test and sawing kerf 


\section{Results and discussion}

\subsection{Static stiffness of wire web}

The feed force measured in the static stiffness test is shown in Fig. 4. The feed force increases with the deformation increases. The relation between the feed force and deformation is linear. The static stiffness curve can be obtained as shown in Fig. 5. The static stiffness of wire web composed of different number of wires could be recognized by the coefficient of linear equation in the figure.

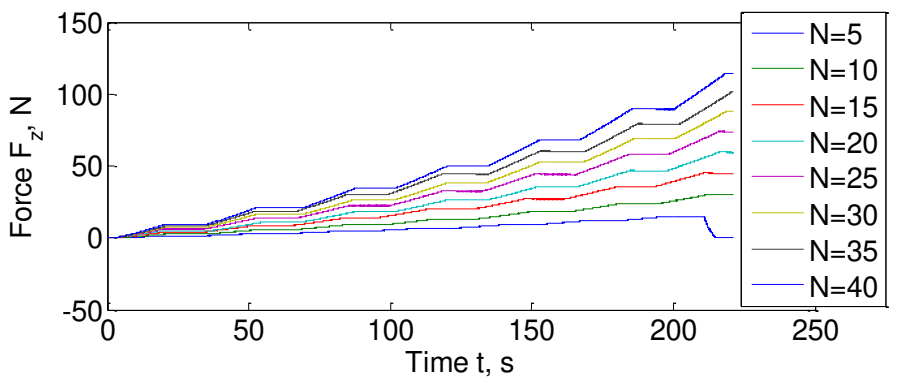

Fig. 4 Measuring forces in the stiffness test of wire web with different number of wire

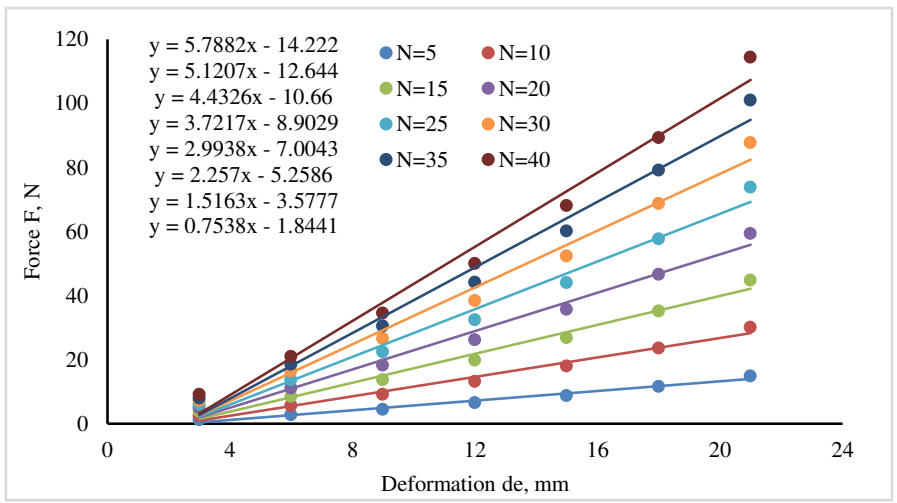

Fig. 5 Stiffness of wire web composed of multiple wires

In addition, the lateral force and force in the cutting direction corresponding to the feed force also show an increasing trend. The lateral force in Fig. 6a shows a linear positive proportional relationship between the lateral force and deformation. However, the relationship between the force and deformation along the wire speed direction is not completely linear, as shown in Fig. 6b.
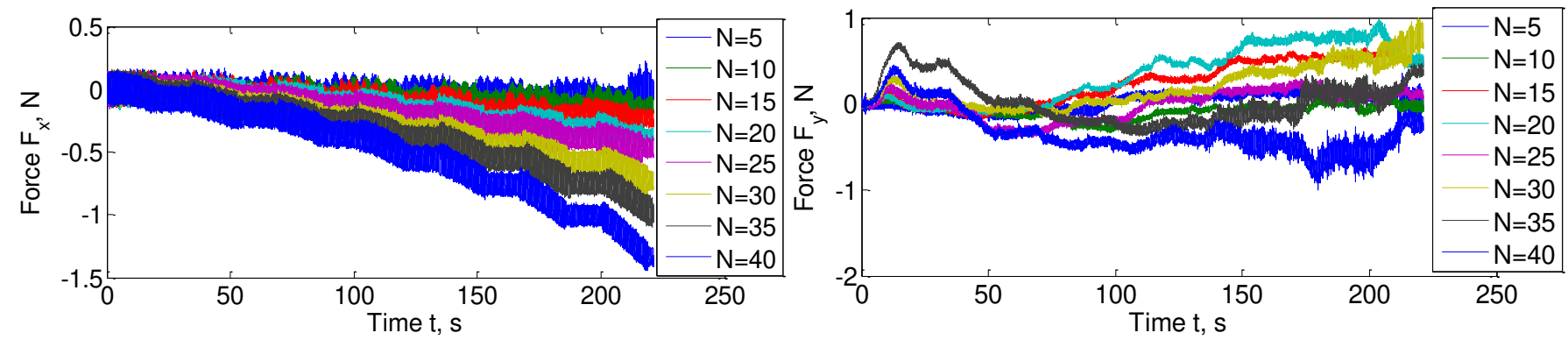

Fig. 6 The lateral force and force on the wire cutting direction vary with the feeding pressure and the number of wires that forms wire web. (a. lateral force; b. force in the cutting direction)

Fig. 7 shows the relationship between the stiffness of wire web and the number of wires forming the wire web. It can be seen that a linear relationship between the stiffness of wire web and the number of wires is existed. In addition, it can be seen from Fig. 7 that the stiffness of a single wire forming the wire web is basically stable between $0.0031-0.0034 \mathrm{~N} / \mathrm{mm}$ in the incremental range from 5 wires to 40 wires. The stiffness of a single wire can be considered as the unit contact stiffness, that is, the unit contact stiffness of the wire is about $0.0033 \mathrm{~N} / \mathrm{mm}$. This law is the same as the stiffness model of machine tool [Error! Bookmark not defined.]. Therefore, the contact stiffness of wire web could be obtained by multiplying the unit 
contact stiffness by the real contact area which is wire number, as shown in Eq.(2).

$$
K=N \times K_{\mathrm{s}}
$$

where, $K$ is the stiffness of wire web; $K_{\mathrm{s}}$ is the stiffness of single wire; $N$ is the number of wire forming wire web.

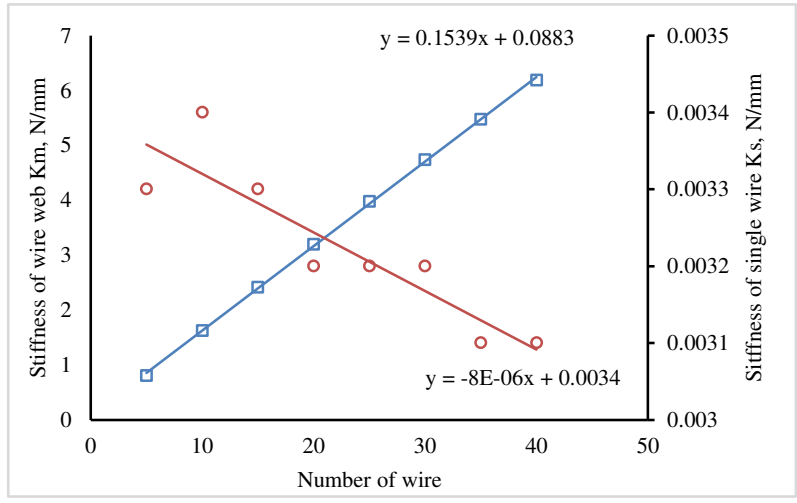

Fig. 7 The relationship between the stiffness of wire web and the number of wires

\subsection{Static stiffness matrices of wire web}

The incremental static stiffness of diamond wire web is defined as the load force required to cause the same amount of deformation. The equation is shown in Eq.(3). The incremental static stiffness of a single diamond wire forming the wire web is expressed as Eq.(4) shows.

$$
\begin{gathered}
K_{\mathrm{i}}=\left(F_{\mathrm{n}}-F_{\mathrm{p}}\right) /\left(D_{\mathrm{n}}-D_{\mathrm{p}}\right) \\
K_{\mathrm{is}}=K_{\mathrm{i}} / N
\end{gathered}
$$

where, $K_{\mathrm{i}}$ is the incremental stiffness of wire web; $F_{\mathrm{n}}$ and $F_{\mathrm{p}}$ are the load of the next position and the previous position, N; $D_{\mathrm{n}}$ and $D_{\mathrm{p}}$ are the deformation of the next position and the previous position, $\mathrm{mm}$. $K_{\mathrm{is}}$ is the incremental stiffness of single wire.

The stiffness matrix between the average incremental static stiffness of a single diamond wire and the number of wires forming the wire web and the feed position of the feeding mechanism is shown in Fig. 8a. With the increase of wire number, the average incremental static stiffness of a single wire decreases slightly; with the increase of the feed position corresponding to wire bow, the incremental static stiffness of a single wire increases greatly.

The stiffness matrix of the incremental static stiffness of the whole wire web with the number of wires and the feed position is shown in Fig. 8b. With the increase wire number, the stiffness of wire web increases. With the increase of feed position, the tension in the wire increases, and the stiffness of the wire web per unit feed distance increases.

It can be concluded that:

(1) Under the condition of the same machine tool, wire and machining technology, the increasing wire number will greatly improve the stiffness of the wire web, and the stiffness of a single wire decreases slightly, which indicates that increasing wire number is helpful to improve the stiffness of the wire web and reduce the loading of a single wire.

(2) With the increase of wire bow, both the stiffness of the whole wire web and the stiffness of a single diamond wire will be greatly increased, and the increasing trend will gradually increase. But this will increase the loading of diamond wire, which is easy to cause wire broken. 

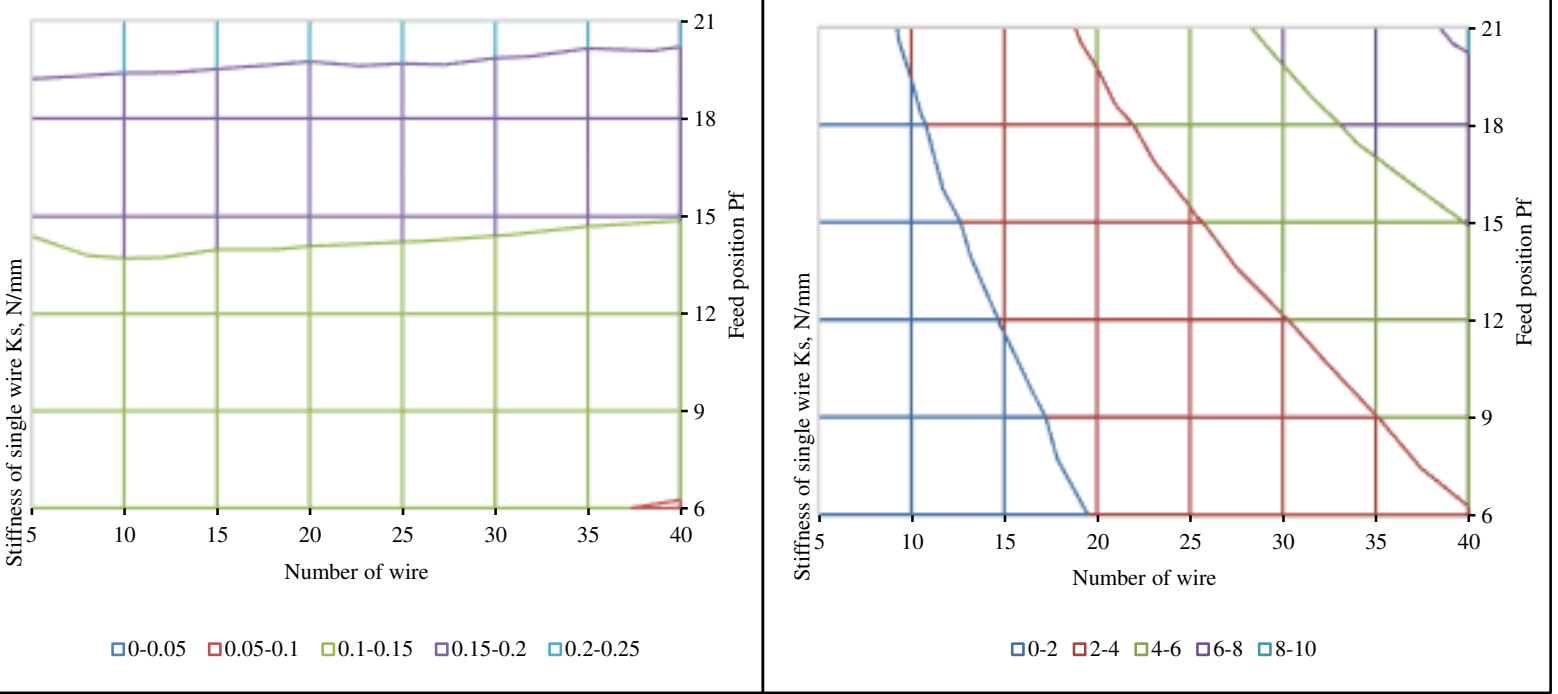

Fig. 8 Stiffness matrices of wire web changes with wire number and feed position. (a. average stiffness of single wire in the wire web; b. stiffness of wire web)

\subsection{Machining accuracy due to wire bow}

The wire bow means insufficient machining that could induce loss of machining accuracy. When the number of wires is 5 , 10 and 15, the change of wire bow fluctuates with the change of feed position. The maximum wire bow of 5 wires is $2-4.2$ $\mathrm{mm}$, while that of 10 wires is $2-4.15 \mathrm{~mm}$, and that of 15 wires is $1.5-3 \mathrm{~mm}$. When the number of wires is 20,30 and 40 , the difference of wire bow is not big under the same feed position, the wire bow is stable at about $2.5 \mathrm{~mm}$, and the maximum difference of wire bow is not more than $0.5 \mathrm{~mm}$.

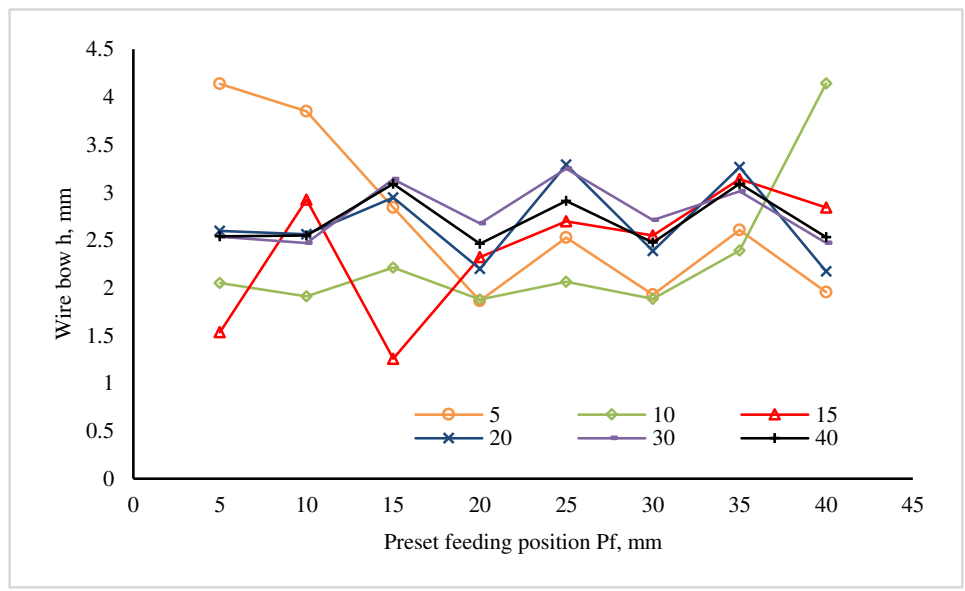

Fig. 9 Wire bow and feed length (a. 5 wires; b. 10 wires; c. 15 wires; d. 20 wires; e. 30 wires; f. 40 wires)

\subsection{Relationship between static stiffness of wire web and wire bow during sawing}

The relationship between the wire bow and its corresponding static stiffness of wire web calculated by the actual sawing kerf is shown in Fig. 10. The wire bow can be stable only when the number of wire forming wire web is more than 20. With the increase of the wire number from 5 to 10, the stiffness of wire web increased and the corresponding wire bow decreased significantly. However, when the number of wires increases from 10 to 15 and from 15 to 20 , the phenomenon is different at different feed positions with wire bow decreases or increases irregularly. However, as the number of wires continues to increases, the wire bow begins to stabilize. With the stiffness of the wire web continues to increase, the wire bow will not change significantly with the increase of stiffness. It shows that one of the conditions to ensure stable sawing is that the number of wire web should exceed at least 20.

The more the number of wires, the higher the stiffness and the higher the stability of deformation. If the stiffness in Fig. 10 is more than $3 \mathrm{~N} / \mathrm{mm}$, the wire bow can be stably predicted for the wire web composed of more than 20 wires. The wire bow corresponding to the number of wire can be seen that the pantograph of 5,10 and 15 fluctuates greatly. 


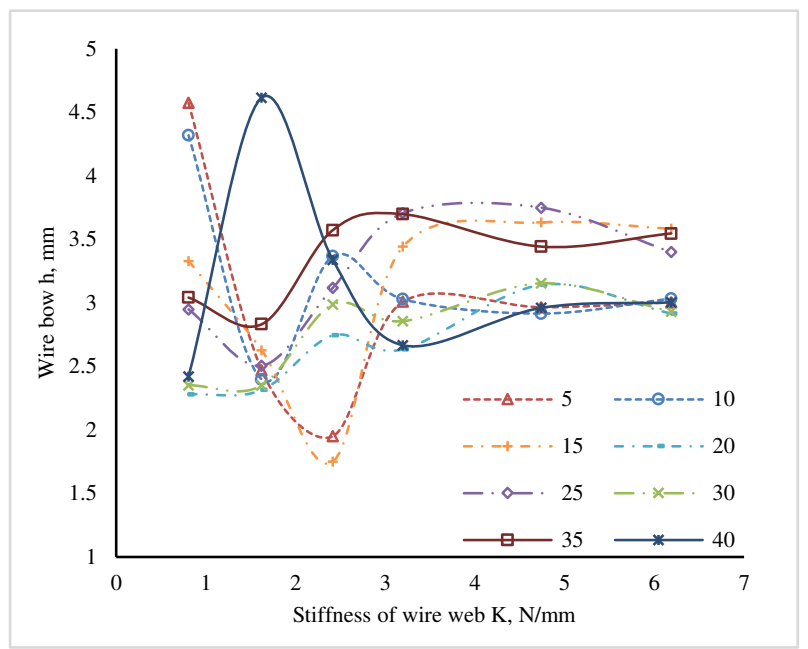

Fig. 10 Relationship between wire stiffness and wire bow at different feed length (a. $5 \mathrm{~mm}$; b. $10 \mathrm{~mm}$; c. $15 \mathrm{~mm}$; d. $20 \mathrm{~mm}$; e. $25 \mathrm{~mm}$; f. $30 \mathrm{~mm}$; g. $35 \mathrm{~mm}$; h. $40 \mathrm{~mm}$ )

It can also be seen from the proportional coefficient between the kerf length $l_{\mathrm{k}}$ and the preset sawing length $l_{\mathrm{p}}$ in Fig. 11 that the proportion coefficient $l_{k} / l_{\mathrm{p}}$ changes when 5,10 and 15 wires form a wire web. Only when more than 20 wires form the wire web, the proportion coefficient between the actual sawing length and the preset sawing length can be stable, that is, when the sawing length is set, the stable sawing length can be output, which is helpful for ensuring and predicting the sawing accuracy.

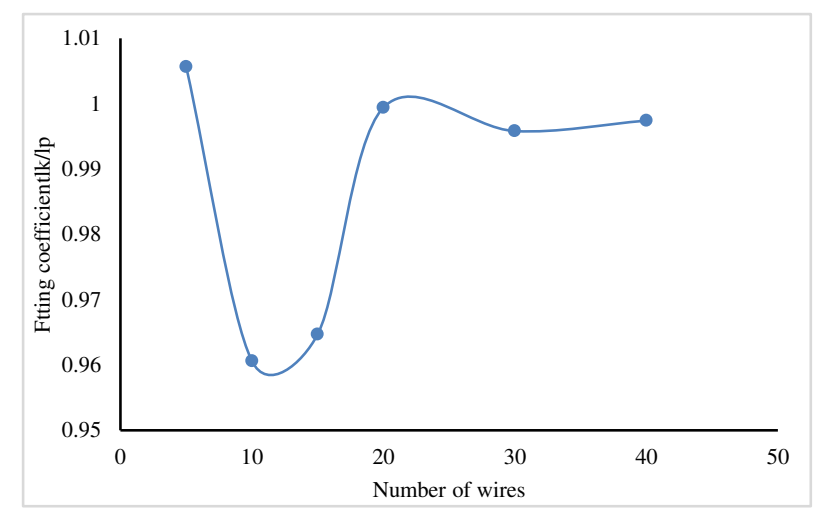

Fig. 11 Coefficient of $l_{\mathrm{k}} / l_{\mathrm{p}}$ and number of wires

The stiffness of wire web can be obtained by calculating the force along the feeding direction of silicon ingot and the preset feed position during cutting, as Fig. 12a shown. It can be seen that the deformation of wire web is also proportional to the feed force during sawing, and the cutting stiffness in Fig. 12b is close to linear with the number of wire that forming wire web.

It can be explained from the static stiffness of the wire web and the cutting stiffness of the wire web. For the multi wire sawing machine, the wire web must contain at least 20 wires to ensure enough stiffness of wire web and can obtain stable cutting accuracy. For single wire and a small number of wire sawing machine, it can realize the rewinding of diamond wire or the arrangement of multi wheel from the aspect machine tool design, which is beneficial to ensure the stiffness and accuracy, reduce the wire bow and machining error. 

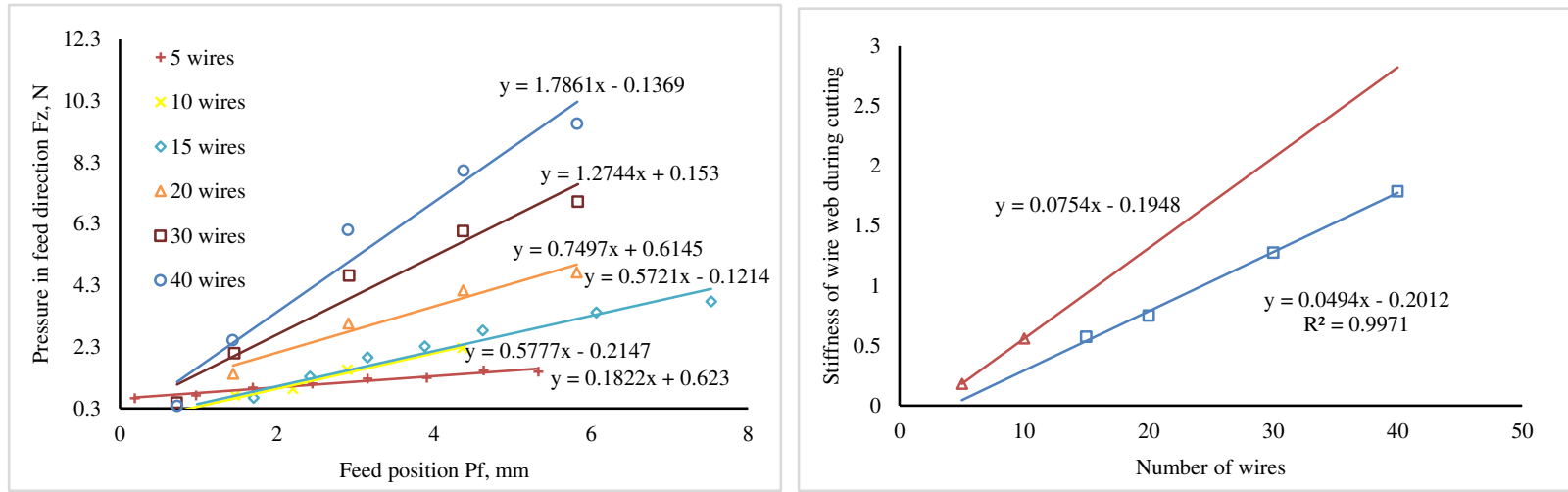

Fig. 12 Relation between feed force and feed position during cutting. (a. stiffness curve of wire web during cutting; b. stiffness of wire web during cutting changes with number of wires)

\section{Finite element analysis of wire deformation}

\subsection{Finite element model}

The static stiffness test is carried out on the finalized equipment of GC630S, but it is inconvenient to change the structure after the equipment is finalized. As the wheel span and wheel diameter affect the stiffness of wire web, the finite element method is used to make qualitative analysis. The variable parameters of FEM are shown in Table 3.

Table 3 Test parameters of finite element analysis

\begin{tabular}{ccccc}
\hline No. & Wheel span $L_{\mathrm{w}}, \mathrm{mm}$ & Wheel diameter $D, \mathrm{~mm}$ & Wire tension $F_{\mathrm{T}}, \mathrm{N}$ & Contact length $l_{\mathrm{c}}$, circle \\
\hline $1-3$ & $370,500,637$ & 218 & 10 & 0.25 \\
$4-6$ & 370 & $180,218,250$ & 10 & 0.25 \\
$7-9$ & 370 & 218 & $5,10,15$ & 0.25 \\
\hline
\end{tabular}

The analysis results of wire web deformation on the condition of wheel span $500 \mathrm{~mm}$, wheel diameter $218 \mathrm{~mm}$, wire tension $10 \mathrm{~N}$, contact length 1/4 winding circle are shown in Fig. 13. Under the preset tension and the uniformly distributed load shown in Fig. 13a on the diamond wire, the deformation along the loading direction is generated to form wire bow as shown in Fig. 13b and c.
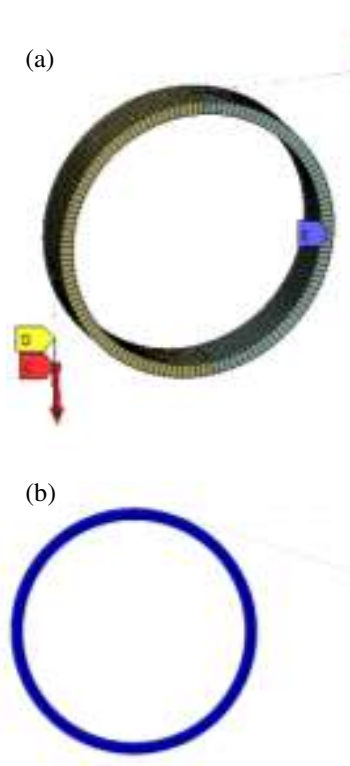
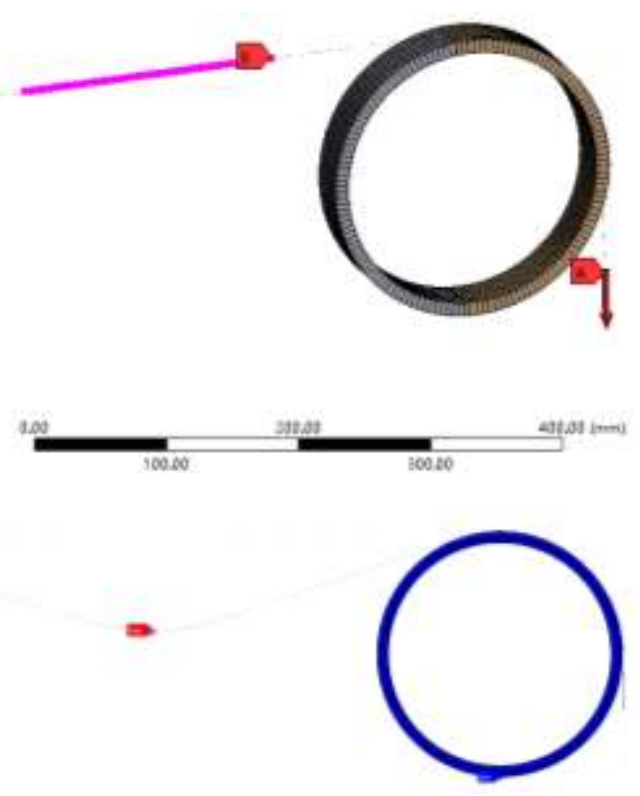


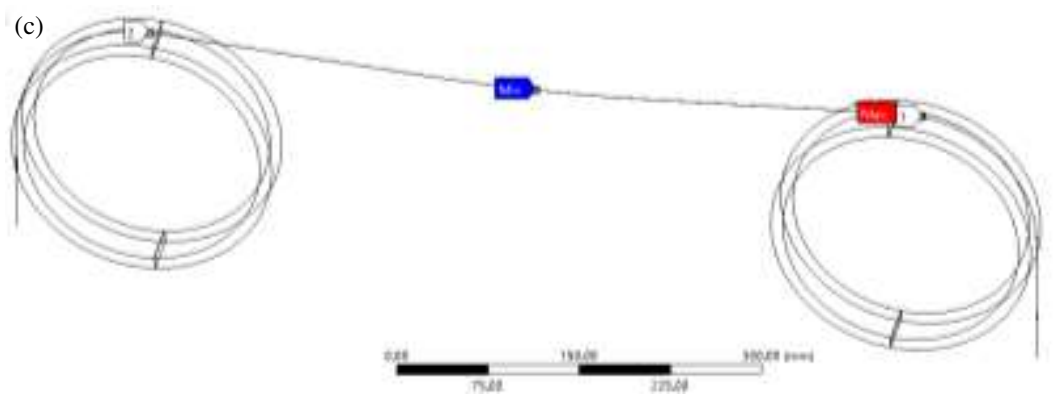

Fig. 13 Deformation of single wire with 1 / 4 winding contact length. (a. loads and constraints of FEM; b and c. single wire deformation)

\subsection{Influence of wheel span, wheel diameter and tension on wire deformation}

The effects of wheel span, wheel diameter and preset tension on wire stiffness are shown in Fig. 14. With the increase of wheel span, the deformation of wire web increases greatly, and the stiffness of wire web decreases sharply. Among the three selected wheel diameters of $180 \mathrm{~mm}, 218 \mathrm{~mm}$ and $250 \mathrm{~mm}$, the wire deformation of wheel diameter of $218 \mathrm{~mm}$ is the smallest and the stiffness of wire web is the best. The larger the preset tension of diamond wire, the smaller the wire deformation and the better the stiffness of wire web.

Therefore, reducing the wheel span and increasing the preset tension on the diamond wire are very helpful to improve the stiffness of wire web. There is an optimal range of wheel diameter for improving the stiffness of wire web. It is not that the larger or smaller the wheel diameter is, the better the stiffness of the wire web is.
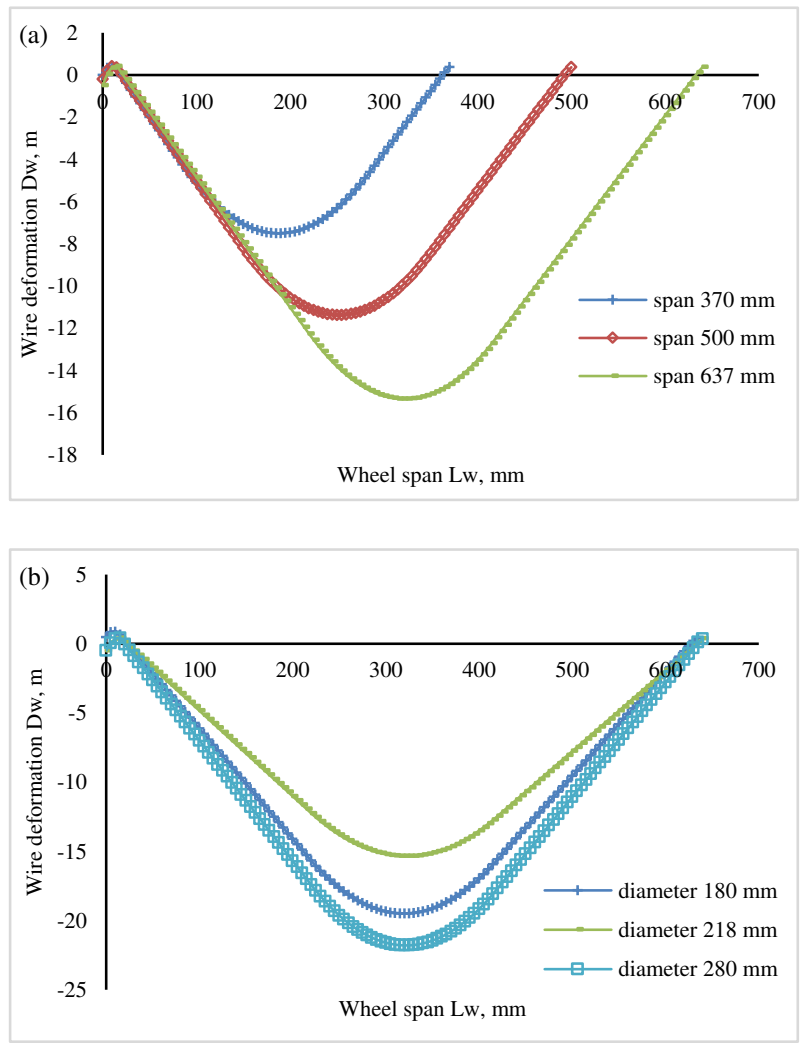


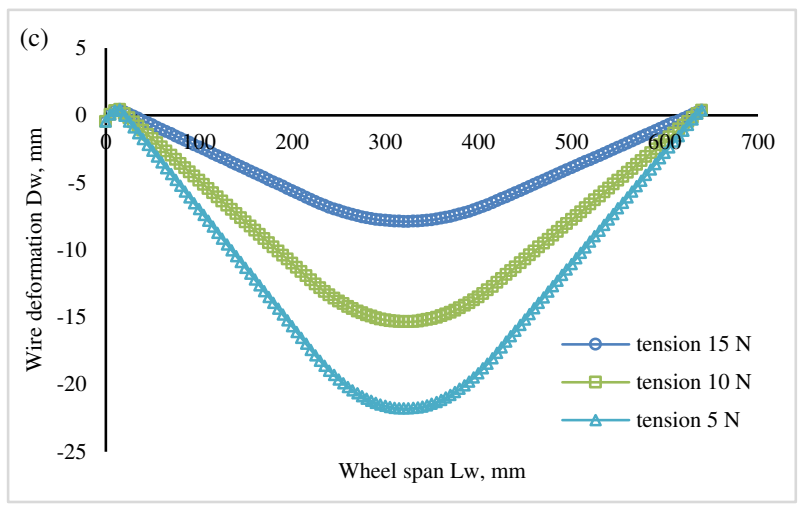

Fig. 14 Deformation of single wire with $1 / 4$ winding contact length varied with wheel span, wheel diameter, and preset tension. (a. variable wheel span; b. variable wheel diameter; c. variable preset tension)

\subsection{Stiffness evaluation of wire web}

$\mathrm{Wu}\left[{ }^{17}\right]$ proposed three performance indices for stiffness evaluation to investigate the stiffness of 5-DOF machine tool changing along different directions with a give machine configuration. In this paper, the evaluation indices are used to evaluate the stiffness of wire web changing with wheel span, wheel diameter, and preset tension.

(1) C1: the lowest stiffness;

(2) C2: the ratio of the highest stiffness to the lowest stiffness;

(3) C3: the average stiffness.

The minimum deformation of the wire web is 0 , so evaluation index of $\mathrm{C} 2$ is not considered. Indexes of $\mathrm{C} 1$ and $\mathrm{C} 3$ are used to evaluate. The results of the evaluation are consistent with the overall distribution trend. The significance of the evaluation indexes is in the stiffness comparison of diamond wire sawing machine tools with different design parameters, such as machine tools produced by different manufacturers, different specifications, different design parameters, and different parts and components.
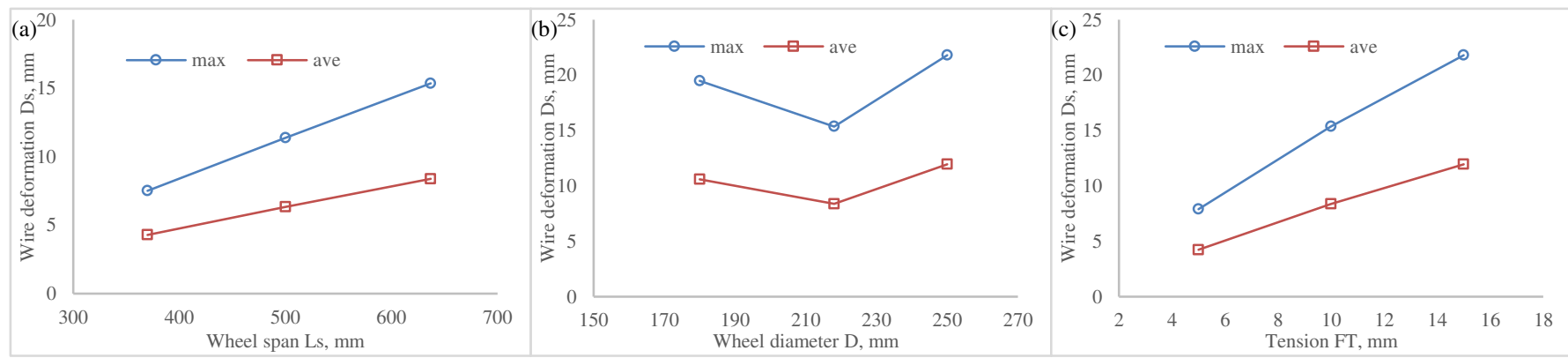

Fig. 15 Stiffness evaluation of wire web. (a. wheel span; b. wheel diameter; c. tension)

\section{Conclusion}

In this paper, the definition of stiffness of wire web was proposed, and it is considered as one of the indexes that determine the machining accuracy of DWS. The research can draw the following conclusions:

(1) The definitions of static stiffness of wire web and cutting stiffness were proposed. The measurement methods of wire web stiffness was provided, including measuring processes and testing instruments.

(2) The static stiffness matrix of the wire web and the single wire were provided by a series of stiffness test. The experimental results show that the number of wires in the wire web cannot be less than 20 in order to ensure enough machining accuracy and make it stable and predictable. Single wire rewinding and adding guide wheel are the measures to improve the stiffness of wire web.

(3) The influences of wire web stiffness on machining process, wire bow, cutting force and machining accuracy were studied. It is found better stiffness of wire web could improve the machining accuracy of diamond wire saw, reduce wire 
bow and its corresponding forces. Meanwhile, the processing is stable and could be predicted.

(4) The finite element method was used to analyze the influence of multiple parameters on the wire web stiffness, including span of cutting wheel, wheel diameter and wire preset tension. Reducing the wheel span and increasing the preset tension of wire could improve the stiffness of wire web. An optimal range of wheel diameter for improving the stiffness of wire web is existed.

(5) The lowest stiffness and the average stiffness are used to evaluate the stiffness of wire web of diamond wire machine tools, which compares the performance of DWS machine tools with different design parameters and information.

\section{Acknowledgements}

The authors acknowledge the support provided by the Development and Construction Fund of National Independent Innovation Demonstration Zone of Shandong Peninsula, Shandong, China, by allowing the facilities to conduct this work.

\section{Declarations}

-Ethical Approval: This work has no potential conflicts of interest. This work has no research involving Human Participants and/or Animals.

-Consent to Participate: Not applicable.

-Consent to Publish: Not applicable.

-Authors Contributions: Jian Qiu: Conceptualization, Methodology, Data curation, Investigation, Formal analysis, Supervision, Writing - original draft, Visualization. Shanbao Zhang and Renpeng Ge: Validation. Guodong Yang and Rilai Fu: Software. He Zhu: Investigation. Yingkui Zou: Equipment.

-Funding: This work was supported by [National Independent Innovation Demonstration Zone of Shandong Peninsula, Shandong, China].

-Competing Interests: The authors declare that they have no known competing financial interests or personal relationships that could have appeared to influence the work reported in this paper.

-Availability of data and materials: All allowed data has been provided in the manuscript.

\section{CRediT authorship contribution statement}

Jian Qiu: Conceptualization, Methodology, Data curation, Investigation, Formal analysis, Supervision, Writing - original draft, Visualization. Shanbao Zhang and Renpeng Ge: Validation. Guodong Yang and Rilai Fu: Software. He Zhu: Investigation. Yingkui Zou: Equipment.

\section{Declaration of Competing Interest}

The authors declare that they have no known competing financial interests or personal relationships that could have appeared to influence the work reported in this paper.

\section{References}


1 Holt A, Thogersen A, Rohr C. Surface structure of mono-crystalline silicon wafers produced by diamond wire sawing and by standard slurry sawing before and after etching in alkaline solutions// Photovoltaic Specialists Conference. IEEE, 2010.

2 Wu H, Melkote SN, Danyluk S. Mechanical Strength of Silicon Wafers Cut by Loose Abrasive Slurry and Fixed Abrasive Diamond Wire Sawing. Advanced Engineering Materials 2012; 14(5):342-348.

3 Wu X, Tan Y, Li J. Surface damage and metal-catalyzed chemical etching investigation of multicrystalline silicon by diamond wire sawing. Solar Energy 2020; 207:609-617.

4 Xiao H, Wang H, Yu N. Evaluation of fixed abrasive diamond wire sawing induced subsurface damage of solar silicon wafers, Journal of Materials Processing Technology 2019; 273: 116267.

5 Suzuki T, Nishino Y, Yan J. Mechanisms of material removal and subsurface damage in fixed-abrasive diamond wire slicing of single-crystalline silicon, Precision Engineering 2017; 50: 32-43.

6 Kono D, Inagaki T, Matsubara A. Stiffness model of machine tool supports using contact stiffness. Precision Engineering 2013; 37(3): 650-657.

7 Sarenac M. Stiffness of machine tool spindle as a main factor for treatment accuracy, The Scientific Journal of FACTA Universitatis 1999; 1(6): 665-674.

8 Yen JY, Chang HM. Performance robustness and stiffness analysis on a machine tool servo design. International Journal of Machine Tools \& Manufacture 2004; 44(5): 523-531.

9 Li B, Hong J, Liu Z. Stiffness design of machine tool structures by a biologically inspired topology optimization method. International Journal of Machine Tools \& Manufacture 2014; 84: 33-44.

10 Majda P, Jastrzębska J. Measurement uncertainty of generalized stiffness of machine tools, Measurement 2021; 170: 108692.

11 Laspas T, Theissen N, Archenti A. Novel methodology for the measurement and identification for quasi-static stiffness of five-axis machine tools, Precision Engineering 2020; 65: 164-170.

12 Huang TY, Lee JJ. On obtaining machine tool stiffness by CAE techniques. International Journal of Machine Tools and Manufacture 2001; 41(8): 1149-1163.

13 Matsubara A, Tsujimoto S, Kono D. Evaluation of dynamic stiffness of machine tool spindle by non-contact excitation tests, CIRP Annals - Manufacturing Technology 2015; 64: 365-368.

14 ASME B5.54 Methods for Performance Evaluation of Computer Numerically Controlled Machining Centers, 2005.

15 Karmakar N, Chetikena H, Venkateshwaran M. Direct Wire-Tension Measurement Based Bowing Correction in Hot Wire Cutting of Polystyrene. Procedia Manufacturing 2020; 48: 230-236.

16 Qiu J, Li XF, Ge RP. Formation mechanism of wire bow and its influence on diamond wire saw process and wire cutting capability. International Journal of Mechanical Sciences 2020: 185: 105851.

17 Wu J, Wang JS, Wang LP, Li TM, You Z. Study on the stiffness of a 5-DOF hybrid machine tool with actuation redundancy, Mechanism and Machine Theory 2009; 44: 289-305 


\section{Figures}

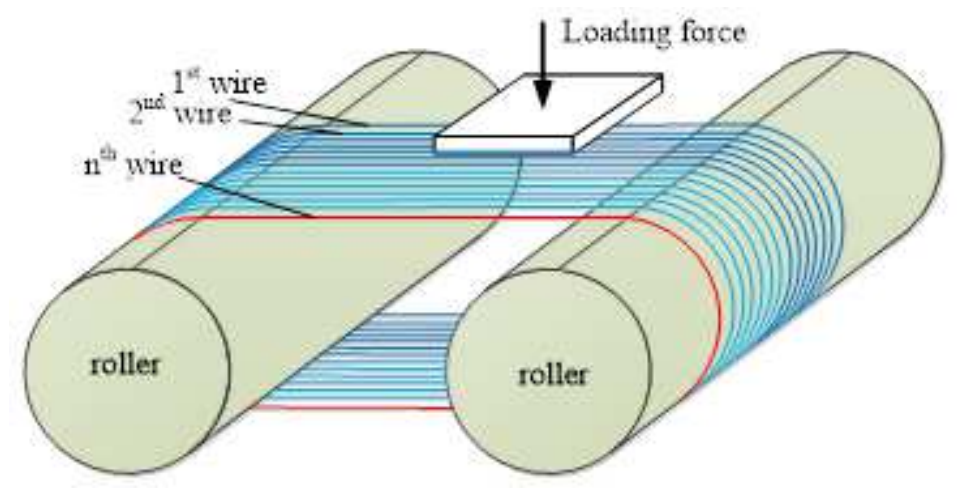

\section{Figure 1}

Stiffness measuring principle of multi-wire sawing web

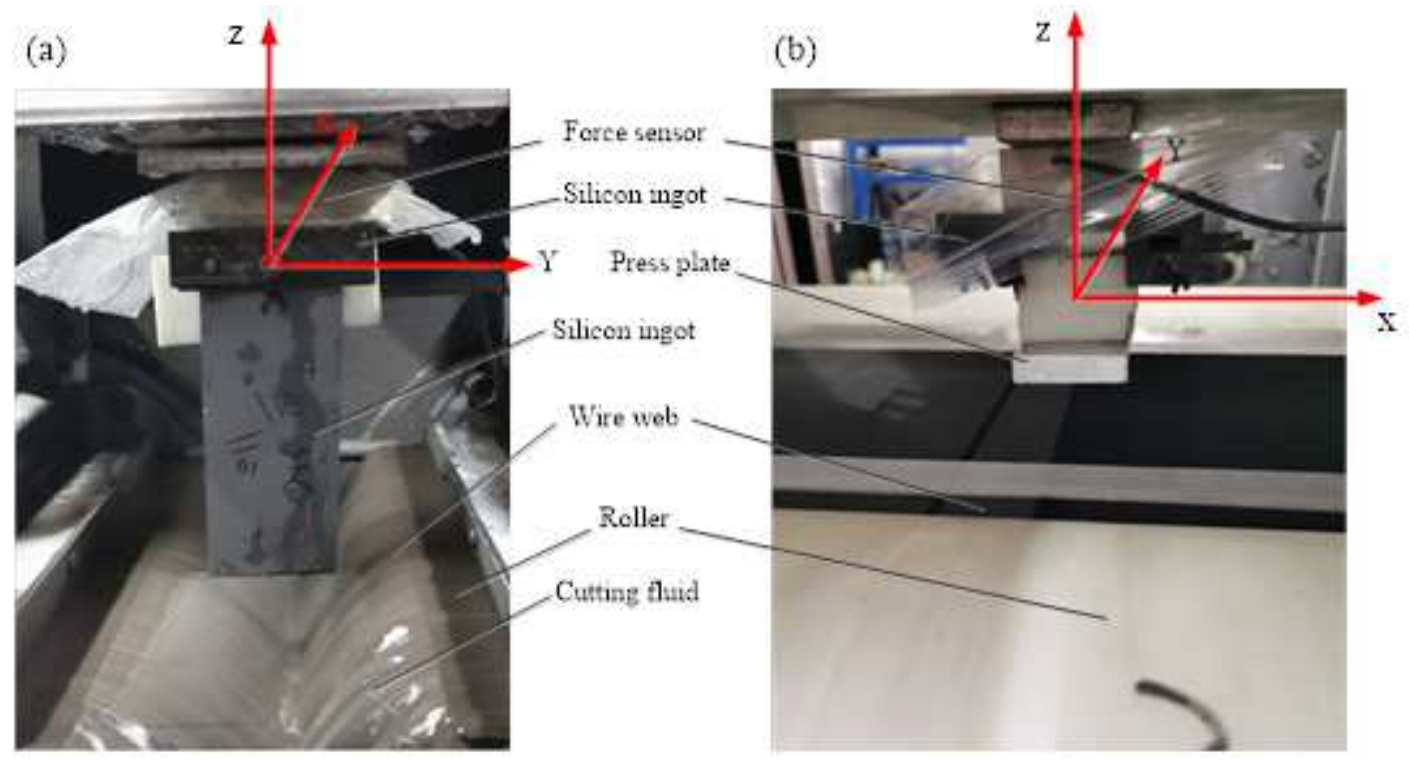

Figure 2

Equipment used in the sawing test. (a. cutting test; b. stiffness test)

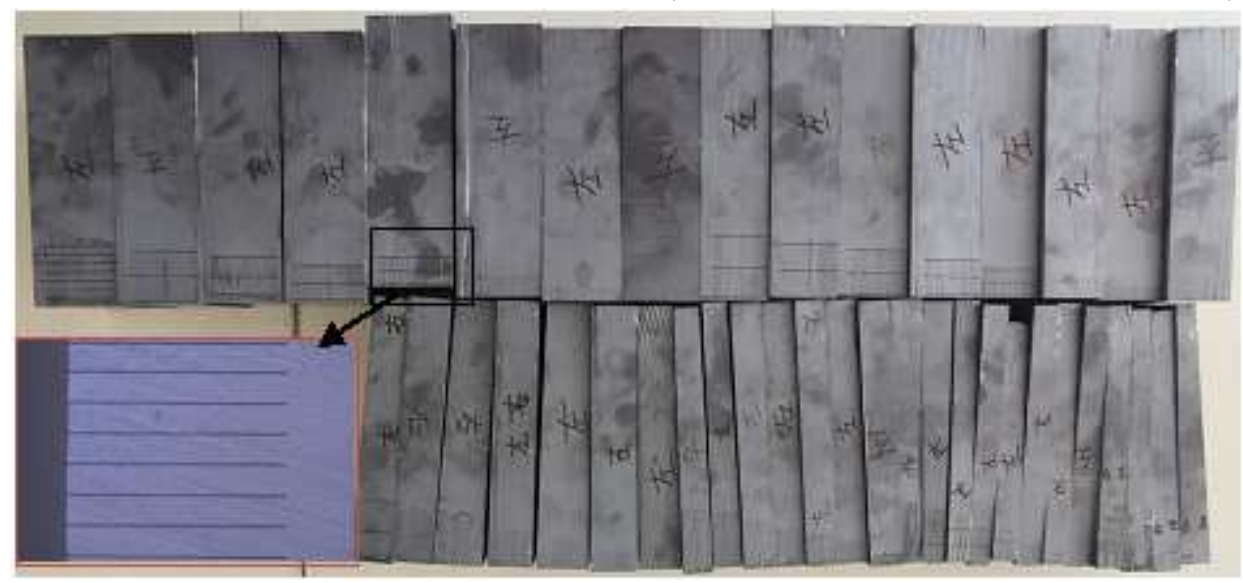

Figure 3 
Silicon workpiece used in the test and sawing kerf

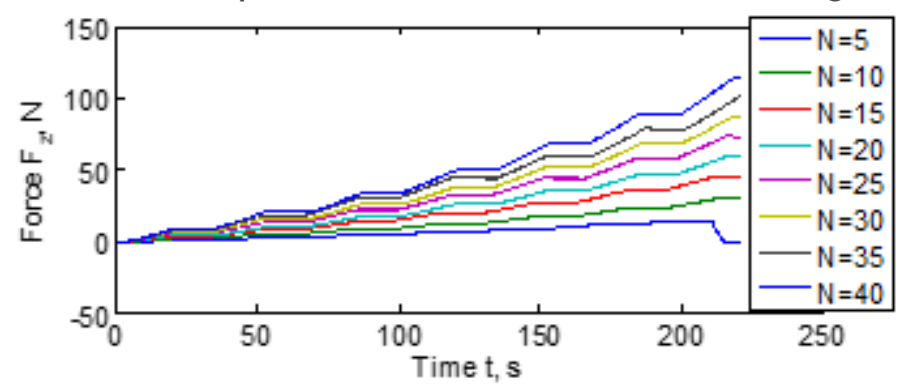

Figure 4

Measuring forces in the stiffness test of wire web with different number of wire

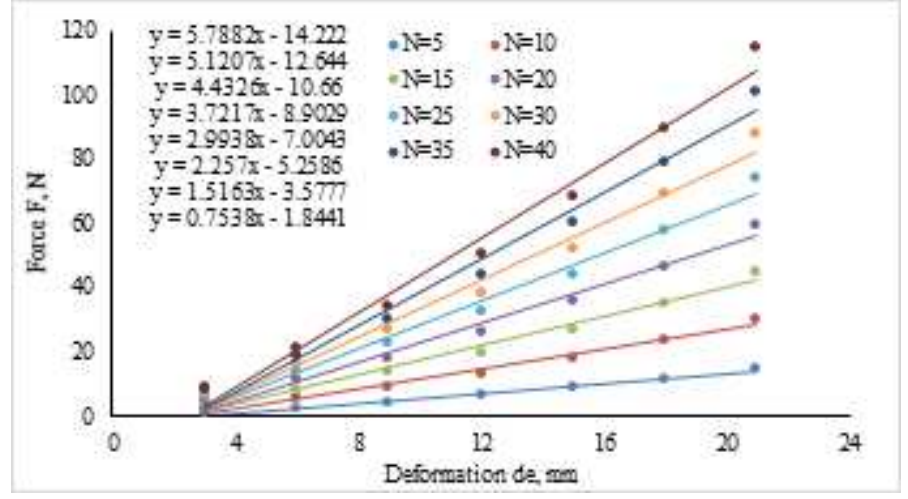

Figure 5

Stiffness of wire web composed of multiple wires
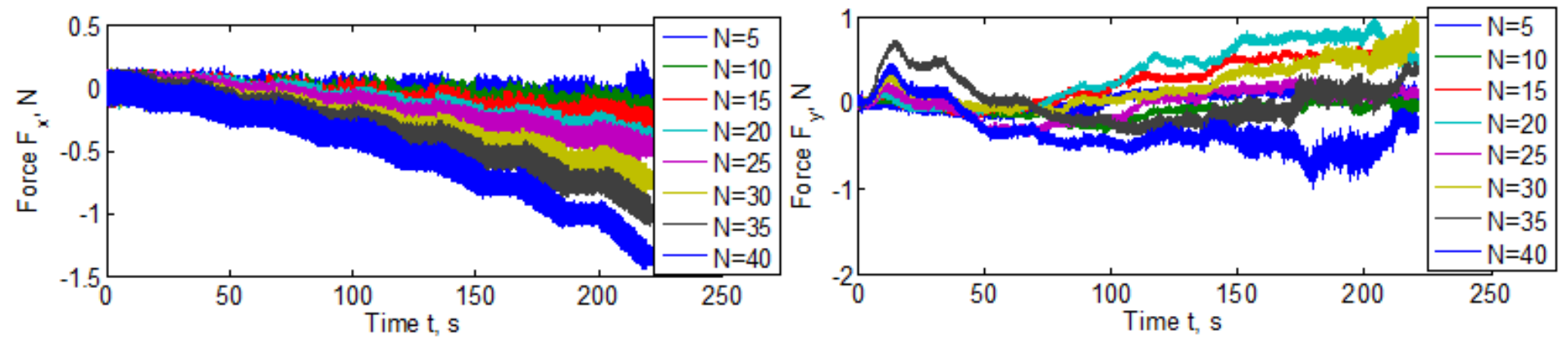

Figure 6

The lateral force and force on the wire cutting direction vary with the feeding pressure and the number of wires that forms wire web. (a. lateral force; $b$. force in the cutting direction) 


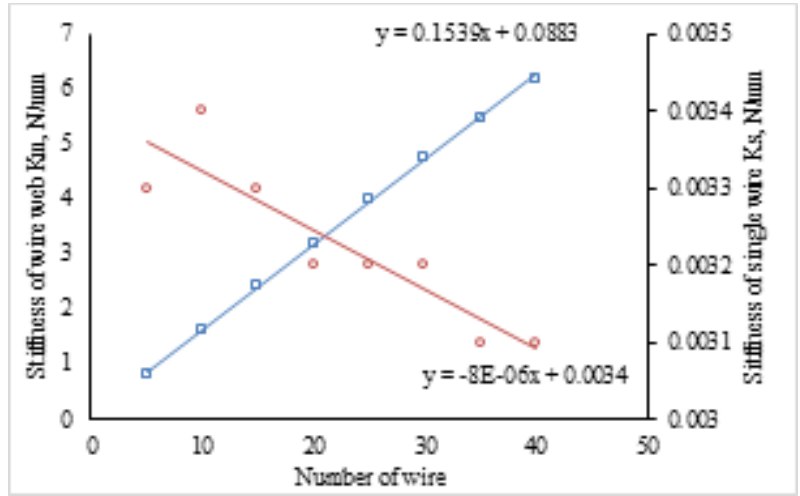

Figure 7

The relationship between the stiffness of wire web and the number of wires

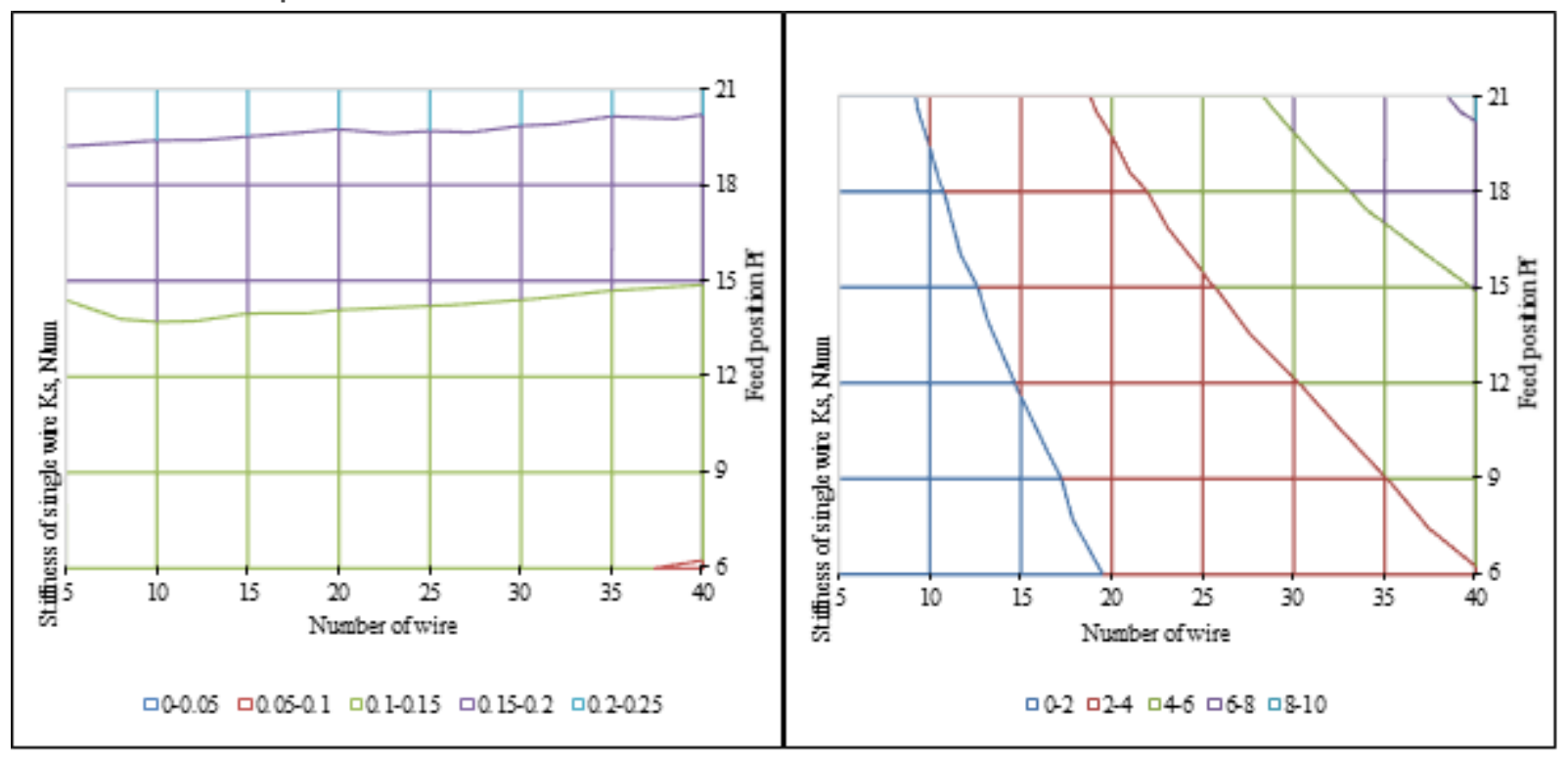

Figure 8

Stiffness matrices of wire web changes with wire number and feed position. (a. average stiffness of single wire in the wire web; b. stiffness of wire web)

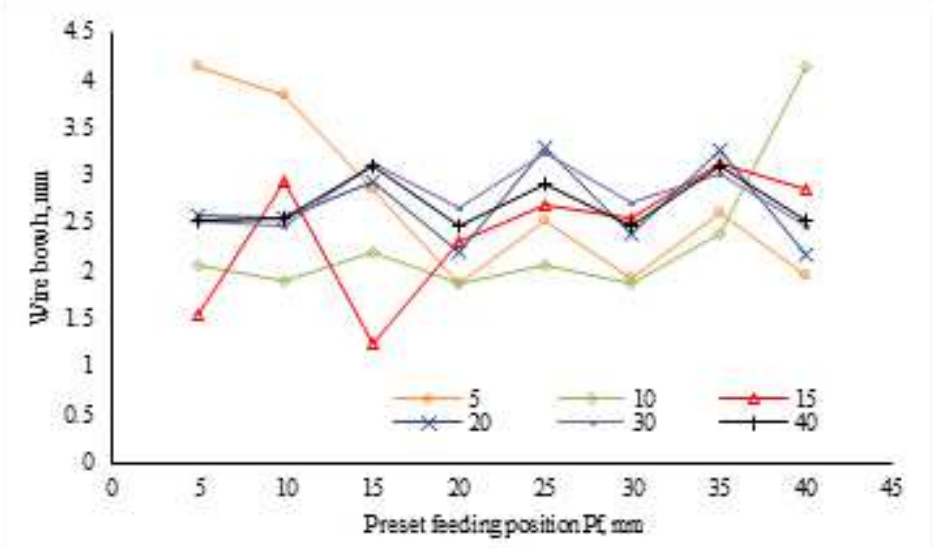

Figure 9 
Wire bow and feed length (a. 5 wires; b. 10 wires; c. 15 wires; d. 20 wires; e. 30 wires; f. 40 wires)

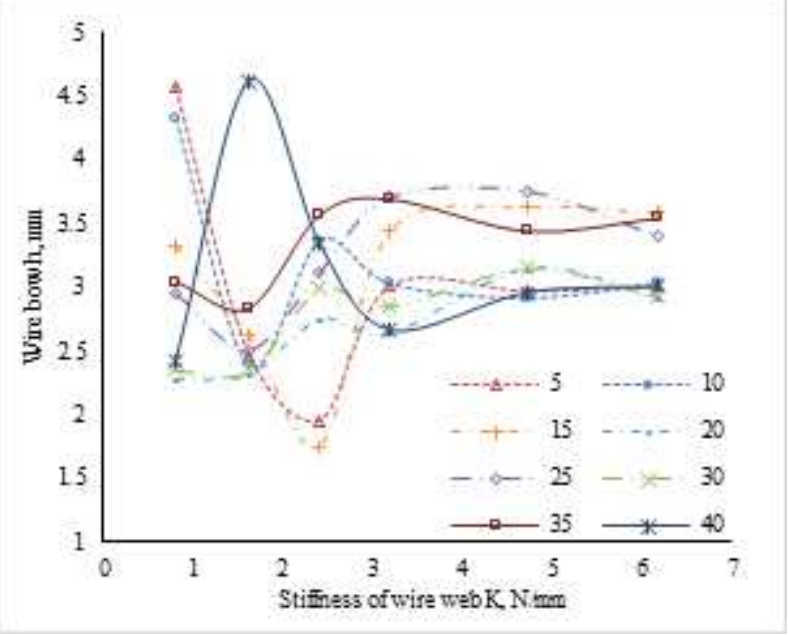

Figure 10

Relationship between wire stiffness and wire bow at different feed length (a. $5 \mathrm{~mm} ;$ b. $10 \mathrm{~mm} ; \mathrm{c} .15 \mathrm{~mm}$; d. 20 mm; e. 25 mm; f. 30 mm; g. 35 mm; h. 40 mm)

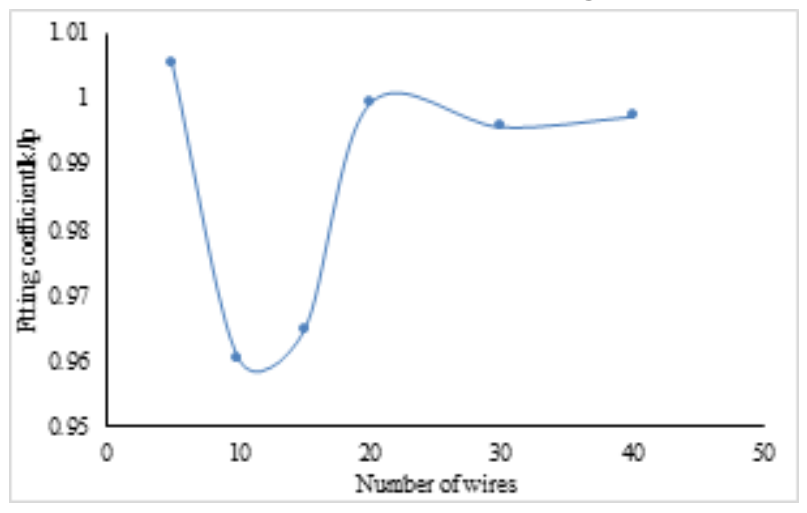

Figure 11

Coefficient of $\mathrm{lk} / \mathrm{lp}$ and number of wires
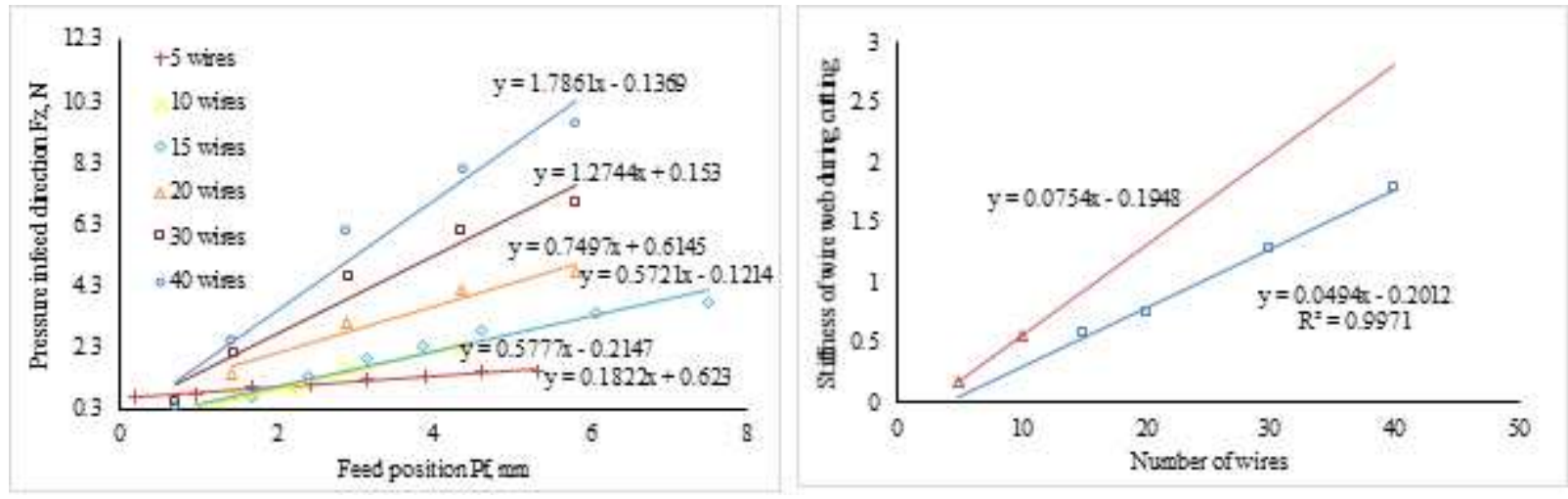

Figure 12 
Relation between feed force and feed position during cutting. (a. stiffness curve of wire web during cutting; b. stiffness of wire web during cutting changes with number of wires)
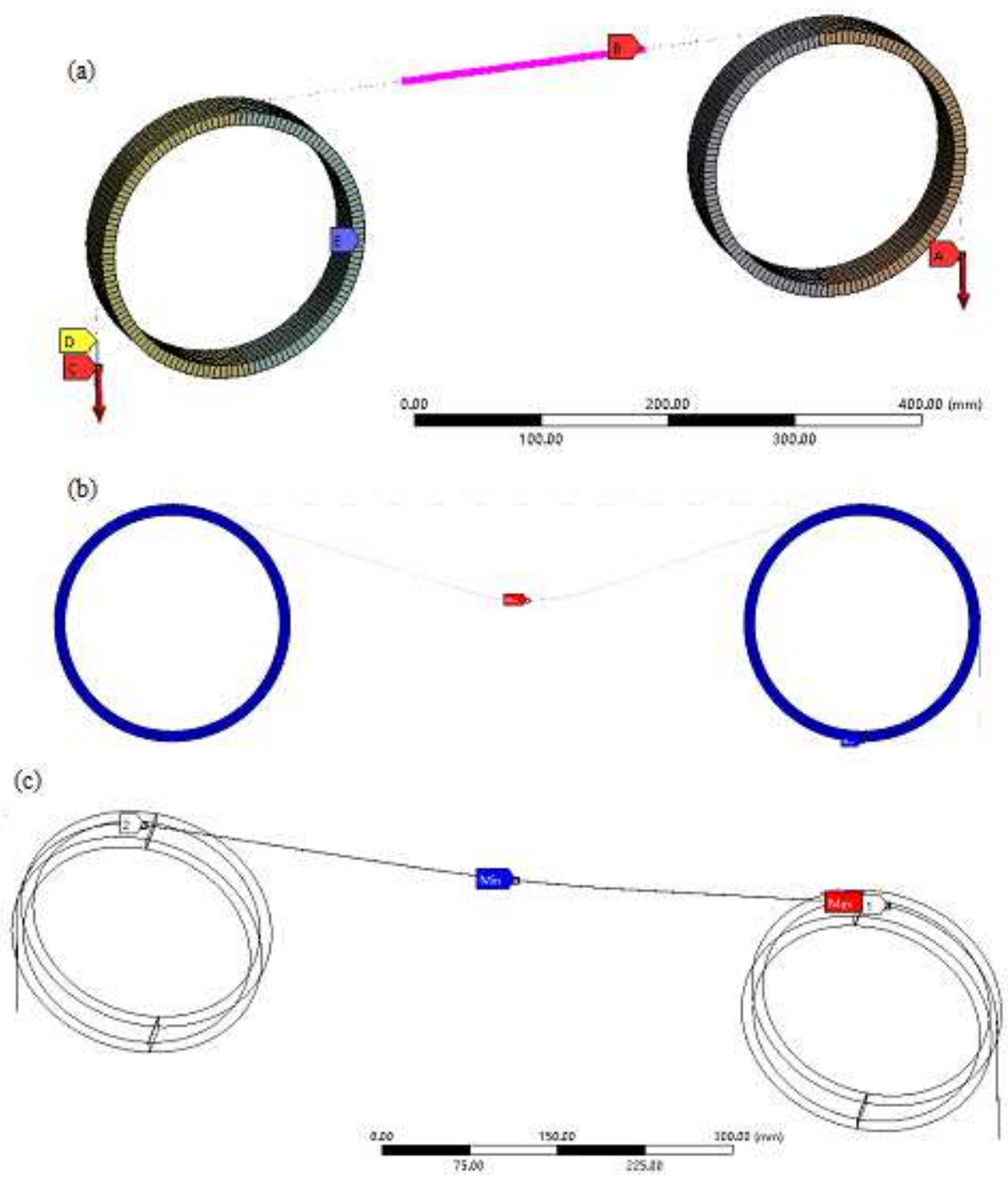

\section{Figure 13}

Deformation of single wire with 1 / 4 winding contact length. (a. loads and constraints of FEM; $b$ and $c$. single wire deformation) 

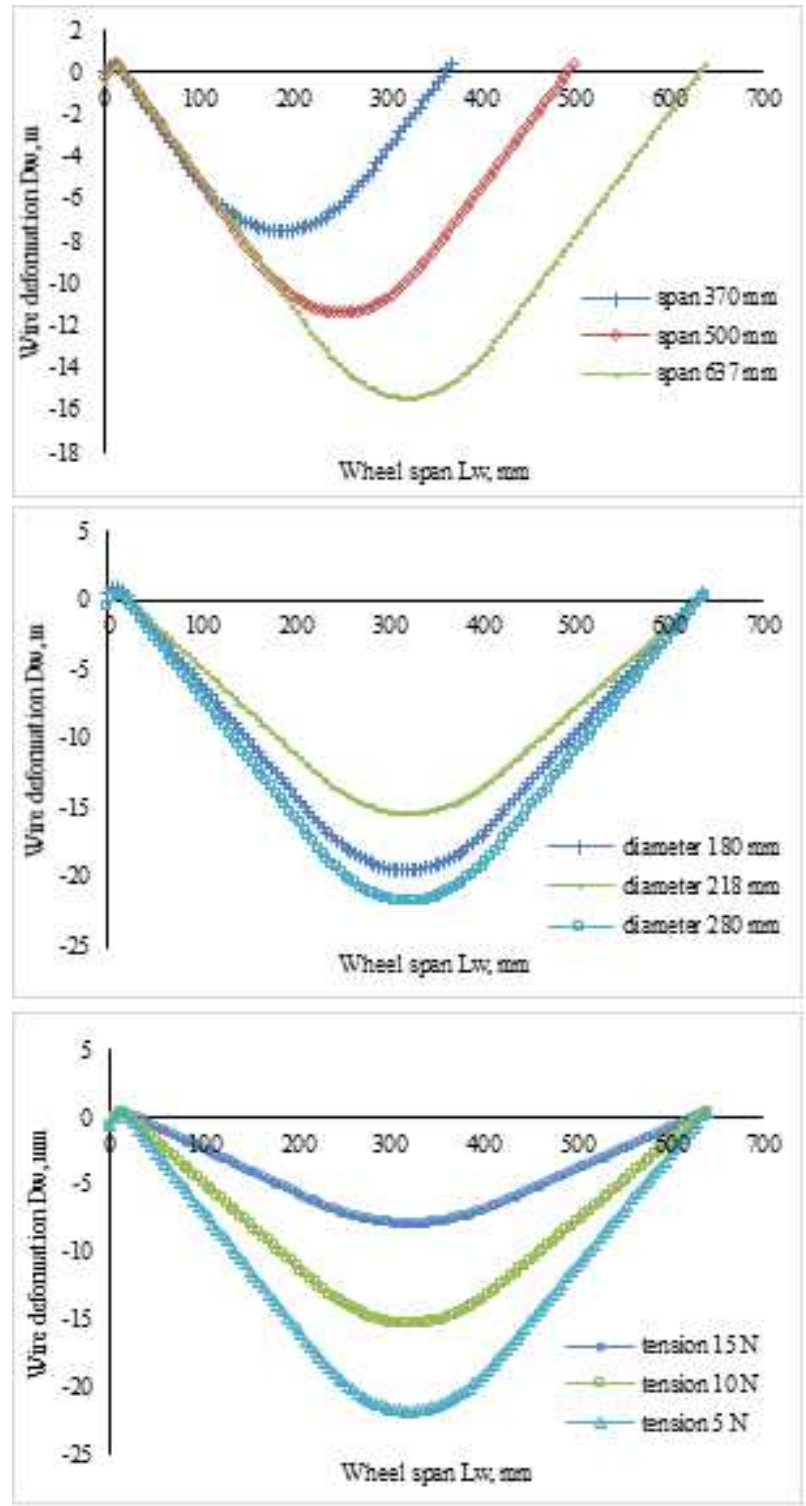

Figure 14

Deformation of single wire with 1 / 4 winding contact length varied with wheel span, wheel diameter, and

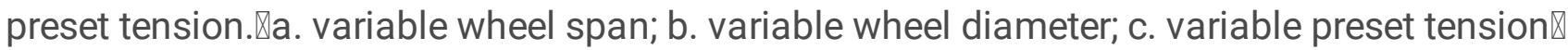
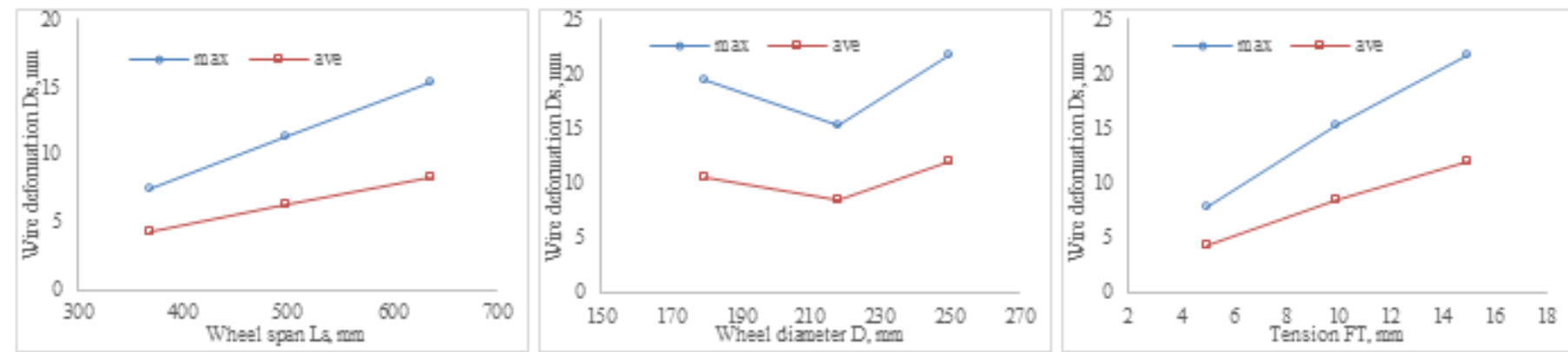

Figure 15

Stiffness evaluation of wire web. (a. wheel span; b. wheel diameter; c. tension) 